\title{
MEMÓRIAS DO BATALHÃO DE LAGOA: PRÁTICA CULTURAL DAS COMUNIDADES RURAIS DO SERTÃO DE ALAGOAS
}

\author{
MEMORIAS DEL BATALLÓN DE LA LAGUNA: PRÁCTICA CULTURAL DE LAS \\ COMUNIDADES RURALES DEL SERTÃO DE ALAGOAS
}

\author{
MEMORIES OF LAGOA BATALHÃO: CULTURAL PRACTICE OF RURAL \\ COMMUNITIES OF SERTÃO DE ALAGOAS
}

\author{
Jailson Costa da SILVA ${ }^{1}$ \\ Marinaide Lima de Queiroz FREITAS ${ }^{2}$
}

\begin{abstract}
RESUMO: Este texto enfatiza o Batalhão de Lagoa, que se caracterizava como uma prática cultural do sertanejo que agregava o cultivo do arroz nas lagoas formadas pelo Rio São Francisco, nas épocas em que as águas eram abundantes. É um recorte de uma pesquisa mais ampla, que utiliza a História oral (ALBERTI, 2008; BOSI, 1994), e integra o Núcleo de Memória da Educação de Jovens e Adultos. Neste recorte apresentamos a memória do referido Batalhão, por meio de narrativas memorialísticas advindas de fontes orais e visuais de um interlocutor, que testemunhou as práticas culturais do Batalhão de Lagoa; dentro das ações do Programa Mobral Cultural, desenvolvidas na zona rural do Município de Pão de Açúcar - sertão de Alagoas. As narrativas foram colhidas por meio de entrevistas e fotografias Cartier-Bresson (1971), Guran, (2011) e Leite (1993). Os dados mostraram que mesmo em meio à forte carga ideológica da Ditadura civil-militar do golpe de 1964, os sujeitos sertanejos agiram enquanto praticantes culturais, demonstrando a resistência das comunidades tradicionais na tentativa de conservarem seus costumes e tradições.
\end{abstract}

PALAVRAS-CHAVE: Prática cultural. Tradição. Memória. Sertão de Alagoas.

RESUMEN: Este texto enfatiza el Batallón de la laguna que se caracterizaba como una práctica cultural del sertanejo y agregaba el cultivo del arroz en las lagunas formadas por el Río São Francisco, en las épocas en que las aguas eran abundantes. Es un recorte de una investigación más amplia, que utiliza la Historia oral (ALBERTI, 2008; BOSI, 1994), e integra el Núcleo de Memoria de la Educación de Jóvenes y Adultos. En este recorte presentamos a la memoria del referido Batallón, por medio de narrativas memorialísticas provenientes de fuentes orales y visuales de un interlocutor, que testimonió las prácticas culturales del Batallón de la laguna, dentro de las acciones del Programa Mobral Cultural, desarrolladas en la zona rural del Municipio de Pão de Açúcar - sertón de Alagoas. Las narrativas fueron recogidas por medio de entrevistas y fotografías Cartier-Bresson (1971), Guran, (2011) y Leche (1993). Los datos mostraron que incluso ante la fuerte carga ideológica de la Dictadura civil-militar del golpe de 1964, los sujetos sertanejos actuaron

${ }^{1}$ Instituto Federal de Alagoas - (IFAL), Piranhas - Alagoas - Brasil. Professor do curso de Licenciatura em Física. ORCID: http://orcid.org/0000-0001-5078-3603. E-mail: jailsonsandes2009@gmail.com

${ }^{2}$ Universidade Federal de Alagoas - (UFAL), Maceió - Alagoas - Brasil. Professora do Curso de Pedagogia. ORCID: http://orcid.org/0000-0003-3659-4165. E-mail: naide12@hotmail.com 
como practicantes culturales, demostrando la resistencia de las comunidades tradicionales en el intento de conservar sus costumbres y tradiciones.

PALABRAS CLAVE: Práctica cultural. Tradición. Memoria. El Sertão de Alagoas.

ABSTRACT: This text emphasizes the Batalhão of Lagoa that was characterized as a cultural practice of sertanejo and added the cultivation of rice in lagoons formed by São Francisco River, in times when waters were abundant. It is a part of a wider research that uses Oral History (ALBERTI, 2008; BOSI, 1994) and integrates the Memory Core of Youth and Adult Education. In this section we present the memory of this Batalhão, through memorialistic narratives from oral and visual sources of an interlocutor, who witnessed cultural practices of Batalhão of Lagoa, within actions of Mobral Cultural Program, developed in rural area of Municipality of Pão de Açúcar - sertão of Alagoas. The narratives were collected through interviews and photographs (CARTIER-BRESSON, 1971; GURAN, 2011; LEITE, 1993). The data showed that even in midst of a strong ideological charge of Civil-Military Dictatorship of 1964 coup, the sertanejos subjects acted as cultural practitioners, demonstrating resistance of traditional communities in an attempt to preserve their customs and traditions.

KEYWORDS: Cultural practice. Tradition. Memory. Sertão of Alagoas.

\section{Introdução}

Em estudos realizados no período de 2011 a 2013 sobre o impacto do Programa de Alfabetização Funcional (PAF), implantado pelo Movimento Brasileiro de Alfabetização $\left(\mathrm{Mobral}^{3}\right)$, na época da Ditadura civil-militar ${ }^{4}$ no Brasil (1964-1985), constatamos que no âmbito do referido Movimento, no sertão alagoano, muitas reflexões ainda permaneciam em aberto, a exemplo das ações culturais realizadas nos municípios do sertão alagoano, como garantia de permanência dos sujeitos alfabetizados no PAF.

Em 2015 iniciamos os estudos sobre as ações culturais desenvolvidas pelo Movimento em foco. Nos achados evidenciamos referências importantes sobre o Batalhão de Lagoa,

${ }^{3}$ No âmbito da educação de adultos, quando da Ditadura civil-militar no Brasil criou-se, em 1967, o Movimento Brasileiro de Alfabetização (Mobral), implementado em 1970 pelo Programa de Alfabetização Funcional (PAF), que perdurou até 1985 . O projeto da ditadura civil-militar passava pelo alargamento do avanço capitalista na constituição do país pela industrialização e, por isso mesmo, necessitava de mão de obra qualificada - o que incluía maior escolarização e redução do analfabetismo entre a mão de obra industrial - para que atraísse multinacionais e que dessem conta de "retirar o Brasil do atraso histórico" a que estava submetido. Esse projeto passava, também, pela melhoria dos níveis de escolarização de jovens e adultos, historicamente interditados do direito à educação no país.

${ }^{4}$ No decorrer do texto, utilizamos o termo Ditadura civil-militar, entendendo que o golpe de 1964 foi fruto de uma coalizão civil e militar. Confirmou-se com a ascensão de um novo bloco no poder, que envolvia a articulação entre o conjunto das classes dominantes, a exemplo a burguesia industrial e financeira nacional e internacional, “[...] bem como uma camada (de caráter civil) de intelectuais e tecnocratas. O espectro de interesses representados por esse conjunto autoriza-nos a qualificá-lo como uma elite”. (GERMANO, 2011, p. $17)$. 
caracterizado como uma prática cultural do sertanejo e que agregava o cultivo do arroz nas lagoas formadas pelo Rio São Francisco, nas épocas em que as águas eram abundantes. As evidências foram advindas por meio de narrativas memorialísticas de fontes orais e visuais de um interlocutor - doravante denominado narrador -, que atuava como supervisor da área do Mobral no sertão.

Esse narrador testemunhou as práticas culturais desenvolvidas no referido Batalhão dentro das ações do Programa Mobral Cultural no Município de Pão de Açúcar ${ }^{5}$, em meio à forte carga ideológica que cercava o imaginário nacional. Nesse sentido, indagamos: quais foram as táticas dos praticantes, acionadas em contextos de Ditadura vivida no sertão de Alagoas?

Compreendemos como De Certeau (2011), que o sertanejo não como um receptor passivo, mas um produtor ativo capaz de sintetizar em sua própria cultura os fragmentos que lhe são doados ou impostos, muitas vezes como forma de controle, como foi o caso da Ditadura civil-militar.

$\mathrm{Na}$ pesquisa entendemos cultura enquanto um campo social caracterizado pela pluralidade, e buscamos, a partir de uma revisão de literatura, sintetizar os sentidos existentes nas práticas culturais dos sujeitos das classes populares, com ênfase nos sertanejos, levando em consideração as representações dessas práticas no cotidiano dessas pessoas. Cotidiano esse marcado historicamente pelo controle social, intermediado por ações ideológicas do Mobral Cultural, mas que se encontrava articulado aos saberesfazeres dos praticantespensantes (PEREZ; AZEVEDO, 2008).

Em nossos estudos, as narrativas têm base nos postulados teóricos de Benjamin (2012), para quem, diferentemente da informação, que só tem valor enquanto é novidade, a narrativa “[...] não se esgota jamais. Ela conserva suas forças e depois de muito tempo ainda é capaz de desdobramentos” (p. 220). Isso porque as narrativas estão sob formas infinitas e presentes em todos os tempos, em todos os lugares, em todas as sociedades, inclusive no contexto de Ditadura civil-militar, acontecida no Brasil com o golpe de 1964.

Bosi (1994, p. 85), ao esclarecer o valor das narrativas, indo ao encontro do nosso estudo, afirma que: “A arte da narração não está confinada nos livros, seu veio épico é oral. O narrador tira o que narra da própria experiência e a transforma em experiência dos que

${ }^{5}$ Município da Mesorregião do sertão alagoano, situada na Microrregião Santana do Ipanema, com uma área de $662,95 \mathrm{~km}^{2}$, com uma população (Censo 2010) de 23.811 habitantes. O Índice de Desenvolvimento Humano (IDHM) - Pão de Açúcar é 0,593, em 2010, o que situa esse município na faixa de Desenvolvimento Humano Baixo (IDHM entre 0,500 e 0,599). A dimensão que mais contribui para o IDHM do município é a longevidade, com índice de 0,793, seguida de renda, com índice de 0,536, e de Educação, com índice de 0,491. (ATLAS DO DESENVOLVIMENTO HUMANO NO BRASIL). 
escutam". É com esse sentimento que temos vivido às experiências narradas, que temos buscado a composição de novas histórias sobre a atuação do Mobral Cultural, no sertão de Alagoas, para o registro da memória da Educação de Jovens e Adultos (EJA).

As narrativas escutadas em cada pesquisa por nós realizada são tidas como fortes experiências humanas, que nas palavras de Alves e Garcia (2008, p. 274), “[...] têm amplitude no tempo e no espaço. São narrativas encontradas que [permitiram] uma ressignificação, uma história diferente das que conhecemos em relação aos conhecimentos [...] políticos oficiais, que são, sobretudo, escritos", no caso específico, os conhecimentos do Batalhão de Lagoa.

Este texto tem a seguinte composição: no primeiro item ocupamo-nos em apresentar as nossas concepções sobre o sertão e os sertanejos enquanto praticantes culturais; na sequência destacamos a importância das fontes orais e visuais e as narrativas que propiciaram a composição de novas histórias; e em seguida focamos o interlocutor-narrador. Por fim, tecemos considerações acerca das práticas culturais do Batalhão de Lagoa, comportamento cultural da comunidade sertaneja, nas décadas de 1970 e 1980.

\section{O sertão e seus praticantes pensantes}

Em nossas pesquisas sobre o sertão, temos apresentado contrapontos à história insistentemente contada acerca desse local e dos seus habitantes. É que as histórias foram e ainda são marcadas pelos discursos hegemônicos que ditaram e continuam a ditar o que lhes convém dizer a respeito do povo sertanejo. O estigma que se tem é que a região sertaneja advém do projeto de dominação colonial, que se perpetua nos discursos contados e apresentados pelas correntes hegemônicas do nosso país. Que lutam constantemente pela dominação dos poderes e dos saberes, desrespeitando as inúmeras diferenças que caracterizam os diversos contextos de um país de dimensões continentais, como temos presenciado nos discursos da gestão presidencial do Brasil assumida em janeiro de 2019.

Isso não aconteceu e não acontece por acaso. É que o conceito de sertão, segundo Melo (2006, p. 81), foi grafado, no princípio, pelo imaginário do colonizador português que, sob o seu ponto de vista, assim o caracterizava. Significou à época da colonização que o "o índio, assim como, posteriormente, o negro, escravo minerador, não eram contados como habitantes, como sujeitos". Os índios traduziram-se em símbolo da barbárie, vistos como "um obstáculo ao avanço da colonização, por isso deveriam ser extintos ou dominados para servirem como escravos". Esse conceito provocou uma dicotomia que caminhou e caminha na seguinte direção: “[...] sertão versus litoral; barbárie versus civilização; natureza bruta versus 
cidade ou sertão versus cidade; avançado, moderno, desenvolvido versus atrasado" (MELO, 2006, p. 83).

O escritor pernambucano Josué de Castro, em sua célebre obra Geografia da fome, na década de 1940, já denunciava os agravantes sociais e políticos deterioradores deste espaço. Ao apresentar aspectos acerca da difícil condição de sobrevivência dos sertanejos, esclarece: "Muito mais do que a seca, o que acarreta a fome no Nordeste é o pauperismo generalizado, a proletarização progressiva, é magreza, é miséria relativa ou absoluta, segundo chova ou não chova no sertão" (CASTRO, 1984, p. 260).

O autor retrata, em sua obra, a penúria que ameaçava a existência dos sertanejos, tornando-os reféns dos processos de exclusão que se propagavam constantemente no âmbito das camadas pobres da sociedade brasileira. Considerou o "fenômeno da fome", como de interesse econômico de uma minoria dominante:

Um silêncio premeditado pela própria alma da cultura: foram os interesses e os preconceitos de ordem moral e de ordem política e econômica de nossa chamada civilização ocidental que tornaram a fome um tema proibido [...] (CASTRO, 1984, p. 20).

É um tema que durante muito tempo tem sido ignorado pelos governantes deste país. Nessa perspectiva, os sujeitos praticantespensantes $^{6}$ da cultura popular são destinados à condição de ingenuidade, e em sua espontaneidade criam dependências dos comandos da cultura das elites, fixando um monopólio nesse campo. Nesse sentido, De Certeau (2012) defende a necessidade da construção de uma política de valorização da cultura, e essa construção só se consolida a partir do reconhecimento da existência de práticas culturais múltiplas e, sobretudo, autônomas, oriundas das classes populares.

É imprescindível o reconhecimento da cultura dos sujeitos ordinários apresentados nos estudos de De Certeau (2011, p. 91), a partir das seguintes características, que os revelam como:

Produtores desconhecidos, poetas de seus negócios, inventores de trilhas nas selvas da racionalidade funcionalista, [...]. Traçam 'trajetórias indeterminadas', aparentemente desprovidas de sentido porque não são coerentes com o espaço construído, escrito e pré-fabricado onde se movimentam. São frases imprevisíveis num lugar ordenado pelas técnicas organizadoras de sistemas.

${ }^{6}$ Entendemos os sujeitos sertanejos como praticantes que recriaram e ressignificaram as ações culturais do Mobral em seus contextos, dado que esses sujeitos são pensantes, o que nos autoriza a utilizar, assim como Oliveira (2012) o neologismo praticantespensantes. 
São os sujeitos anônimos que, em suas trajetórias culturais, reinventam, por meio de táticas, novas maneiras de viver no mundo marcado pelo poder, escapando das determinações dos lugares que lhes são impostos, transformando esses lugares em espaços que, por eles praticados, ganham novos sentidos, certamente incoerentes com as imposições colocadas pela ordem.

Freire (2011) também contribuiu com fios que conduzem à tessitura dessa discussão ao apresentar as diversas "formas de estar sendo" dos sujeitos das classes populares, em suas peculiaridades. $\mathrm{O}$ autor destaca os costumes conservados por estes sujeitos, referindo-se especificamente às pessoas que vivem no campo:

[...] ainda quando as áreas camponesas estejam sendo atingidas pelas influências urbanas [situação típica das décadas em estudo], através do rádio, da comunicação mais fácil por meio das estradas que diminuem as distâncias, conservam quase sempre, certos núcleos básicos de sua forma de estar sendo (FREIRE, 2011b, p. 56).

Essa reflexão é tida como valiosa neste trabalho, sobretudo por não estigmatizar os sujeitos das classes populares como seres totalmente passivos das ações colonialistas dos representantes da cultura dominante. Buscamos nas entrelinhas das análises de Freire (2011) e De Certeau (2011) a possibilidade, que para muitos é inviável, de se pensar a autonomia dos sujeitos das classes subalternas, frente à imposição da cultura dominante, em um contexto de intensa intervenção e controle do povo, em suas maneiras de agir e pensar.

Nesse sentido, Freire (2011) também nos convida a pensar sobre a descrença no homem simples, o que em suas análises tem reforçado o equívoco da absolutização da ignorância dos indivíduos das classes populares. O autor vai mais longe, apontando: "para que os homens simples sejam tidos como absolutamente ignorantes, é necessário que haja quem os considere assim" (FREIRE, 2011, p. 57).

$\mathrm{Na}$ trilha dessas reflexões reafirmamos a nossa percepção, em relação aos sertanejos enquanto sujeitos vitimados por esta absolutização da ignorância, provocada por relações verticais historicamente constituídas. Tais relações são provocadoras do silêncio e da introjeção desse mito da ignorância absoluta.

Compreendendo os sertanejos como esses sujeitos ordinários e praticantes, descritos por De Certeau (2011), buscamos apresentar a maneira como os sertanejos que participaram das ações do Mobral Cultural interpretaram, lidaram e ressignificaram as informações dispostas pelo Movimento em questão, naquele contexto de Ditadura, que por sua vez representava um poder ideológico. 
De Certeau (2011) nos alerta sobre os usos que os sujeitos fazem cotidianamente dos artefatos culturais que lhes são impostos/doados: "Os conhecimentos e as formas simbólicas impostas são objetos de manipulação pelos praticantes que não seus fabricantes". Neste estudo, os sertanejos são tidos como esses sujeitos praticantespensantes, capazes de transformar consumo em uso, ressignificando, em seus espaços culturais, os objetos de consumo que lhes são apresentados.

\section{Testemunhos orais e fotográficos: narrativas sobre o Batalhão de Lagoa}

Nessa trajetória, mais uma vez, a abordagem da história oral foi nossa aliada, com base nos postulados teóricos de Alberti (2008) e Bosi (1994), pois ela vem desempenhando um papel fundamental na reconstrução de fatos históricos, uma vez que nos permitiu e vem nos permitindo: “[...] realizar entrevistas gravadas com pessoas que puderam testemunhar sobre acontecimentos, conjunturas, instituições, modos de vida ou outros aspectos da história contemporânea" $\left(\mathrm{CPDOC}^{7}\right)$. O tipo de entrevista que operamos também neste estudo com o narrador foi denominada de entrevista temática. Esse tipo de entrevista dedica-se “[...] prioritariamente sobre a participação do entrevistado no tema escolhido" (ALBERTI, 2008, p. 175).

Junte-se isso à interação das fontes orais com outras fontes - as fotografias -, na perspectiva da composição de uma rede documental, pois: "Na análise de entrevistas de História oral deve-se ter em mente também outras fontes - primárias e secundárias; orais, textuais, iconográficas etc. - sobre o assunto estudado" (ALBERTI, 2008, p. 187, grifos nossos).

Entre os meios de expressão existentes a fotografia sobressai-se, uma vez que "[...] é o único que fixa para sempre o instante preciso e transitório [...]" (CARTIER-BRESSON, 1971, p. 21). Trata-se da retenção de momentos que não voltam a acontecer, e que, por mais que fiquem gravados nas lembranças de quem os vivenciou, não são possíveis de ser revelados, porque as memórias dos protagonistas da história não são reveláveis em laboratórios fotográficos.

Fixada na fotografia, a memória de um instante é preservada, guardada como um tesouro que carrega em si a preciosidade de um tempo que não se resgata. Mas se reconstrói a partir das imagens que evidenciam características de um acontecimento histórico e

${ }^{7}$ Concepção da metodologia da História oral do Centro de Pesquisa e Documentação de História Contemporânea do Brasil. Disponível em: http://cpdoc.fgv.br/acervo/historiaoral. Acesso em: jan 2020. 
possibilitam o aguçamento da imaginação dos que não viveram tal momento, bem como o reencontro de um passado presente nas lembranças dos sujeitos que protagonizaram o fato histórico.

Em uma das nossas pesquisas sobre o Mobral (2011 a 2016), conseguimos reunir um corpus documental composto de 87 fotografias $^{8}$ e caracterizado por imagens diversas, que apresentam comportamentos fotográficos variados. Em sua grande maioria, de profissionais desconhecidos, e entre elas surgiu a possibilidade da reconstrução da história do Batalhão de Lagoa. Os estudos de Leite (1993, p. 165), mostram que essa categoria de imagens tem grande valor, uma vez que: "feita para recordar atos da vida, em sua continuidade, está carregada de conotações tanto mais fortes quanto mais condicionadas pelo mundo exterior".

Essa possibilidade atrelou-se às falas de interlocutores entrevistados, que foram enfáticos ao indicarem os trabalhos desenvolvidos no município de Pão de Açúcar, sobretudo, o ex-supervisor de área dessa cidade do sertão alagoano Ele que fazia o intercâmbio entre os municípios, por meio das ações desenvolvidas pelo Subsistema de Supervisão Global $\left(\right.$ SUSUG $\left.^{9}\right)$, implantado no Mobral a partir de 1973, e objetivava a integração de uma rede de recursos humanos que chegava a todos os municípios do país. Nossos interlocutores nos deram pistas - lembrando que é uma característica da história oral -, de como chegar a Hélio Silva Fialho, historiador, bacharel em direito e jornalista, que descreveu em suas narrativas as ações que foram desenvolvidas pelo Movimento no município de Pão de Açúcar.

Antes de narrar suas ações culturais, que foram desenvolvidas no município acima mencionado, com destaque ao Batalhão de Lagoa, situado no Povoado Santiago, o nosso interlocutor, numa entrevista que durou uma hora e quarenta minutos, fez questão de dizer que ingressou no Mobral no início de 1980, em substituição a Edval Augusto de Melo ${ }^{10}$, um exilado político e, anteriormente, um dos guerrilheiros de Caparaó ${ }^{11}$.

\footnotetext{
${ }^{8}$ Todas as fotografias fazem parte do conjunto de memórias de seu acervo pessoal dos entrevistados, e foram cedidas no momento das entrevistas e disponibilizadas para publicação.

${ }^{9}$ O Sistema de Supervisão Global estruturava-se em três níveis, havendo um supervisor fixo em cada município, denominado Encarregado da Supervisão Global; um supervisor volante, denominado Supervisor de Área que [tinha] como responsabilidade, uma média de 5 municípios, e um supervisor que [integrava] as informações em nível estadual e, por isso, era denominado Supervisor Estadual (BRASIL, 1975, p. 7).

${ }^{10}$ Edval Augusto de Melo, marinheiro reformado e ex-exilado político, natural de Pão de Açúcar, AL, faleceu em 2011 aos 79 anos. Ver mais detalhes no Documentário Caparaó, no qual Edval Melo concedeu entrevista. Disponível em: https://www.youtube.com/watch?v=_kmFrku0YPk.

${ }^{11}$ A Guerrilha de Caparaó, ocorrida entre fins de 1966 e início de 1967, foi um movimento de resistência armada à Ditadura civil-militar de 1964, que teve como ponto geográfico estratégico a região do Parque Nacional de Caparaó - divisa dos estados de Minas Gerais e Espírito Santo. Tido como primeiro movimento armado que se levantou contra o regime militar, entre os muitos outros nomes que fizeram parte da história da Guerrilha de Caparaó destaca-se o pãodeaçucarense Edval Augusto de Melo.
} 
Por meio da sua narração colhemos que o Batalhão de Lagoa (Figura 1 a seguir) era uma manifestação cultural importante naquele povoado, e consistia em uma organização dos sertanejos em torno do cultivo do arroz. Agregava muitos alunos do Programa de Alfabetização do Mobral (PAF). Considerando que, à época, essa tradição cultural passou a ser reconhecida nas atividades culturais do Movimento.

Figura 1 - Batalhão de Lagoa - Povoado Santiago, Município de Pão de Açúcar, AL, agosto de 1981.

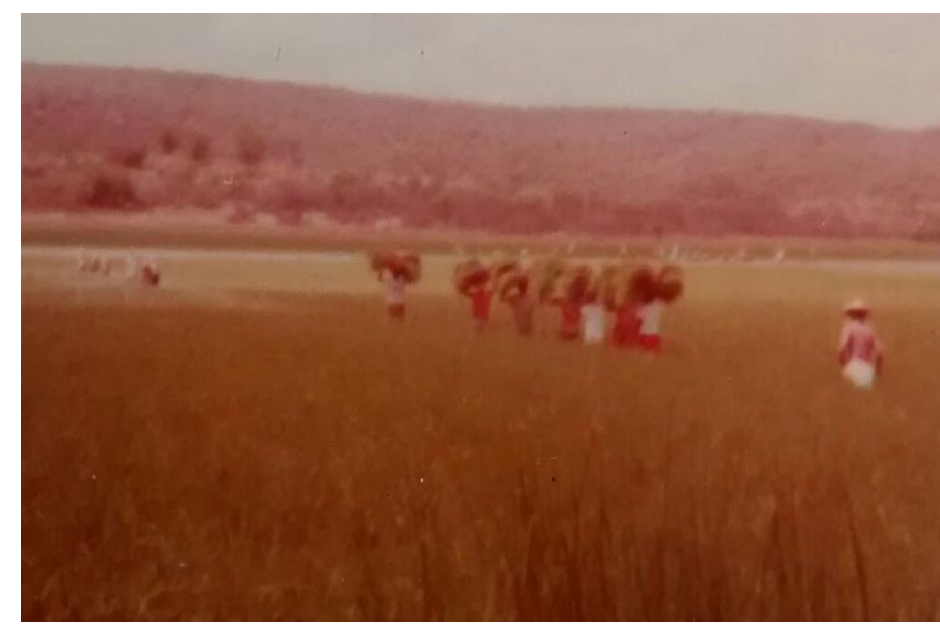

Fonte: Arquivo pessoal de Hélio da Silva Fialho, ex-supervisor de área do Mobral.

Encerrada a entrevista, o narrador comprometeu-se em garimpar seus arquivos em busca de mais fotografias da época, a exemplo da que aparece acima, que demonstra "o Batalhão adentrando, levando potes, bacias, cestos cheios de sementes de arroz, a planta já arrancada da lagoa [...]" para a continuidade do cultivo. Aparecem na imagem dois grupos: segundo o interlocutor, um composto por mulheres e outro por homens, que se mantinham afastados durante a realização das atividades. No seu trabalho de busca de memórias o informante concedeu-nos dez belíssimas fotografias, algumas trabalhadas como fontes neste artigo.

\section{Entre cantos e labuta: o Batalhão de Lagoa}

Com base na oralidade do narrador e nos registros fotográficos que datam do início dos anos de 1980, abrimos um espaço para comentar sobre a experiência de um grupo de pessoas pertencentes à comunidade sertaneja do povoado Santiago, situado nas imediações do município de Pão de Açúcar - sertão alagoano.

Em sua organização, o Batalhão de Lagoa tem no seu espaço a abertura para cooperação entre os membros das comunidades participantes, que se ajudam no labor diário, 
bem como comungam dos festejos populares que resistem às padronizações colonizadoras, como as manifestações populares que ainda são recorrentes nas comunidades mais tradicionais no sertão alagoano.

Thompson (1998) nos dá respaldo para confirmar essa resistência das comunidades tradicionais que, mesmo poucas, ainda conservam seus costumes e tradições. Esclarece o pesquisador que esses campos de resistências são pontuais e, geralmente, são evidenciados em comunidades de pequenos agricultores e pescadores, nos quais o ritmo do trabalho ainda é ditado pela natureza e não pelo tempo do mercado; a lógica que impera nesses contextos é a da necessidade de execução das tarefas diárias, mencionadas na citação abaixo, que o autor chama de ritmos "naturais" de trabalho:

[...] cuidar das ovelhas na época do parto e protegê-las dos predadores; vacas devem ser ordenhadas; deve-se cuidar do fogo e não deixar que se espalhe pelas turfas (e os que queimam carvão devem dormir ao lado); quando o ferro está sendo feito, as fornalhas não podem apagar (THOMPSON, 1998, p. 271).

Apesar da obrigatoriedade no cumprimento das tarefas, os sujeitos das classes populares ainda não se renderam ao tempo do capital, ou seja, ao tempo do relógio, o que os tornam peculiares e, sobretudo, resistentes aos mandos do capitalismo em suas ocupações rurais.

A fotografia a seguir demonstra os sertanejos em uma das suas experiências de trabalho, fortemente distinta pelas tradições e costumes peculiares à cultura do povo do Nordeste; a exemplo, os mutirões, também conhecidos como batalhões, na região do sertão alagoano. Conhecido pelo encontro de diversas pessoas que se reúnem pelo trabalho e, ao trabalharem, entoam cantos definidos pelo Dicionário Musical Brasileiro como: "Cantos usados durante o trabalho e destinados a diminuir o esforço e a aumentar a produção, os movimentos seguindo os ritmos do canto" (ANDRADE, 1989, p. 108).

Os mutirões ou batalhões são entendidos, neste artigo, como forma de criação cultural do povo. Carlos Rodrigues Brandão (1995, p. 209), ao descrever as características de um mutirão, esclarece que esta tarefa coletiva contém os elementos do dom de:

[...] dar, receber, retribuir. Há um convite regido pela necessidade de um trabalho coletivo, associado ao desejo de realizá-lo não através de empresa paga, mas por meio de uma coletivização de um serviço vivido em um dia, como um rito. Há uma resposta obrigatória ao convite, por razões de parentesco, vizinhança, amizade, associada ou não a uma dívida anterior e equivalente de parte de um convidado (quem o convida participou antes de um mutirão em suas terras). 
O dom da doação, o dom da coletividade, do companheirismo (Figura 2), acaba por amenizar os desgastes físicos do trabalho braçal.

Figura 2 - Batalhão de Lagoa: plantação de arroz na extinta Lagoa de Santiago, agosto de 1981

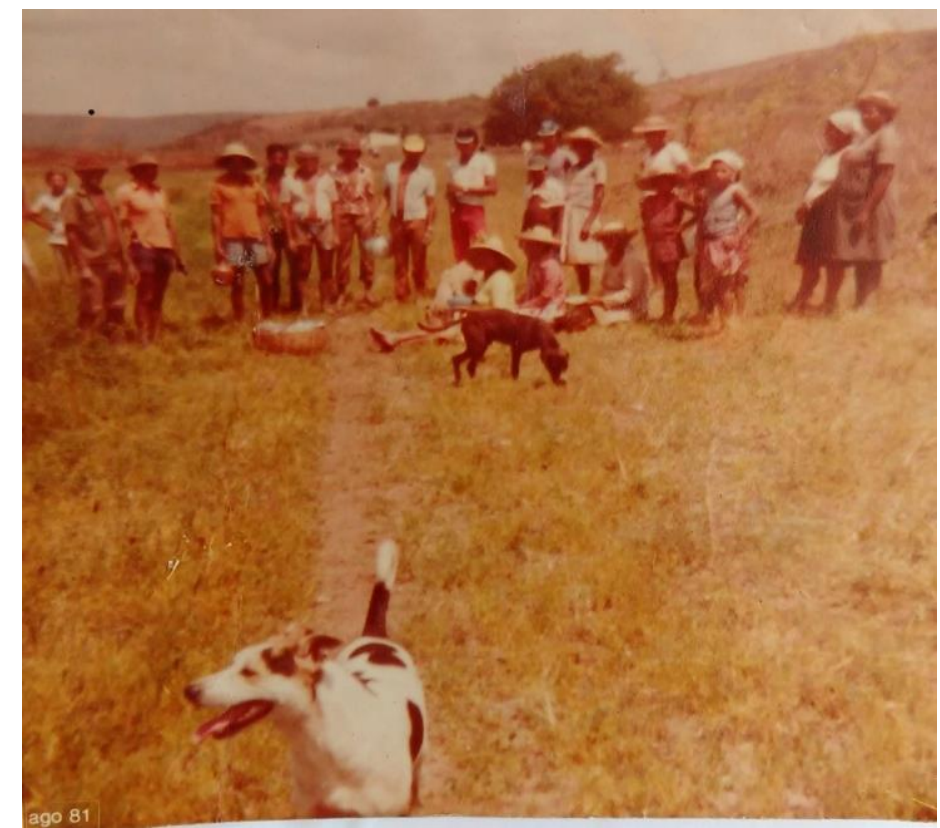

Fonte: Arquivo pessoal de Hélio da Silva Fialho, ex-supervisor de área do Mobral.

A fotografia “[...] é, por natureza, eminentemente descritiva” (GURAM, 2011, p. 80), registra a labuta diária dos sertanejos, alguns deles, ex-alunos do PAF/Mobral. O narrador, ex-supervisor de área dessa região sertaneja, e localizado nas nossas incursões pelo campo da pesquisa, de forma enfática com o olhar nas demais fotos expostas, disse:

Estas fotografias foram tiradas em outubro de 1981, durante o trabalho do tradicional Batalhão de Lagoa, um grupo de moradores locais que trabalhava no plantio de arroz, em cujas terras da Lagoa do Santiago o arroz era plantado de meação, isto é, da quantidade de arroz que era colhido, $50 \%$ eram destinados ao dono das terras e os outros $50 \%$ ficavam com o dono da plantação. A cada dia, a depender da área de terra a ser plantada e replantada, o mesmo grupo (o Batalhão de Lagoa) saía da casa do dono da plantação (morador) para 'fechar a terra' de determinada pessoa (morador), onde o grupo passava o dia inteiro trabalhando e cantando as cantigas tradicionais do folclore local. (HÉLIO FIALHO, exsupervisor de área do Mobral).

Os costumes, tradições e rituais também são narrados pelo interlocutor, que conta com entusiasmo e orgulho ter vivenciado com esses sujeitos as experiências culturais de um contexto peculiar na história dos trabalhadores do referido povoado, e continua de forma emocionada, ao dizer: 
Geralmente o grupo saía da casa do 'posseiro' para a área de terra a ser plantada na lagoa. Todos saíam cantando em alta voz as cantigas do cancioneiro ribeirinho dos batalhões de lagoa, sendo que o dono da plantação (meeiro ou meeira, a depender do gênero), carregava consigo uma bandeira branca erguida sobre uma vara. Ao chegar no local desejado (na área de terra a ser plantada, na lagoa, os membros do grupo adentravam nas águas da lagoa e a bandeira branca era fincada à margem (na terra) onde seria plantada. Para superar a longa e árdua jornada de trabalho sob o sol causticante, o batalhão cantava continuamente - uns puxavam alguns versos e outros respondiam. E assim passavam o dia inteiro trabalhando. Na hora do crepúsculo, o batalhão retornava da mesma maneira que partira pela manhã. Ao chegar à casa da 'meeira do dia', os membros começavam a dançar uma espécie de 'coco de roda' ou 'pagode de coco'. Durante e após o fechamento da terra (até retornar para casa), os membros do batalhão (mulheres e homens) bebiam vinho, cachaça e comiam rubacão com carne guisada (gado ou galinha de capoeira). E assim, os tradicionais batalhões de lagoa, muito comuns nas localidades ribeirinhas que viviam da plantação de arroz), resistiram ao tempo, porém, não resistiram ao desaparecimento das lagoas do Velho Chico. (HÉLIO FIALHO, ex-supervisor de área do Mobral).

Os rituais citados nas narrativas do interlocutor nos deixam margem para inferir sobre as diversas possibilidades de interpretação das experiências e tradições dos sujeitos sertanejos. Dentre essas experiências, destaca-se o modo de viver a vida em um contexto em que a coletividade prevalecia e os costumes eram repassados para as gerações mais jovens. A exemplo das crianças que acompanhavam seus pais nas jornadas de trabalho, como descreve a fotografia 2, na qual as crianças aparecem seguindo os costumes, vestem-se como os adultos, protegem suas cabeças do sol assim como fazem os mais velhos e, certamente, participavam e aprendiam os rituais - versos e canções populares -, típicos de um batalhão.

Brandão (2002), ao dar ênfase aos saberes populares presentes na cultura de cada comunidade, enfatiza que:

Dentro da cultura do povo há um saber; no fio de história que torna esse saber vivo e continuamente transmitido entre pessoas e grupos há uma educação. É a partir destas redes de trabalho popular de cultura que o educador popular deve situar o seu trabalho através da cultura. Ele não tem o direito de invadir, como colonizador bem-intencionado, esses domínios de educação e saber da cultura do povo. (BRANDÃO, 2002, p. 97, grifo nosso).

A palavra educação refere-se no seu sentido amplo às relações sociais cotidianas estabelecidas no interior das comunidades. Ou seja, os saberes impregnados na cultura do povo das comunidades rurais do sertão.

O depoente complementa que os comes e bebes fazem parte do ritual que corrobora as observações de Brandão (1995), ao dizer que manifestação festiva se sobressai ao trabalho em 
si, e que comer e beber é parte do costume nos tradicionais mutirões rurais: "E honra do 'dono' que não falte 'comida e bebida'. Que sobre a olhos vistos depois que todos forem embora. Que se comente 'a fartura e o tratamento'. Saber 'tratar' é um preceito de muito valor e é a expressão usada para significar a hospitalidade”. (BRANDÃO, 1995, p. 211).

A imagem a seguir demonstra o ritmo de trabalho do batalhão, orquestrado pelo canto e pelo esforço coletivo dos camponeses que, em nome da tradição, ancorada na convivência solidária, desenvolvem trabalho produtivo e, sobretudo, cooperativo.

Figura 3 - Serviço de eito - Batalhão de Lagoa - Povoado Santiago, agosto de 1981.

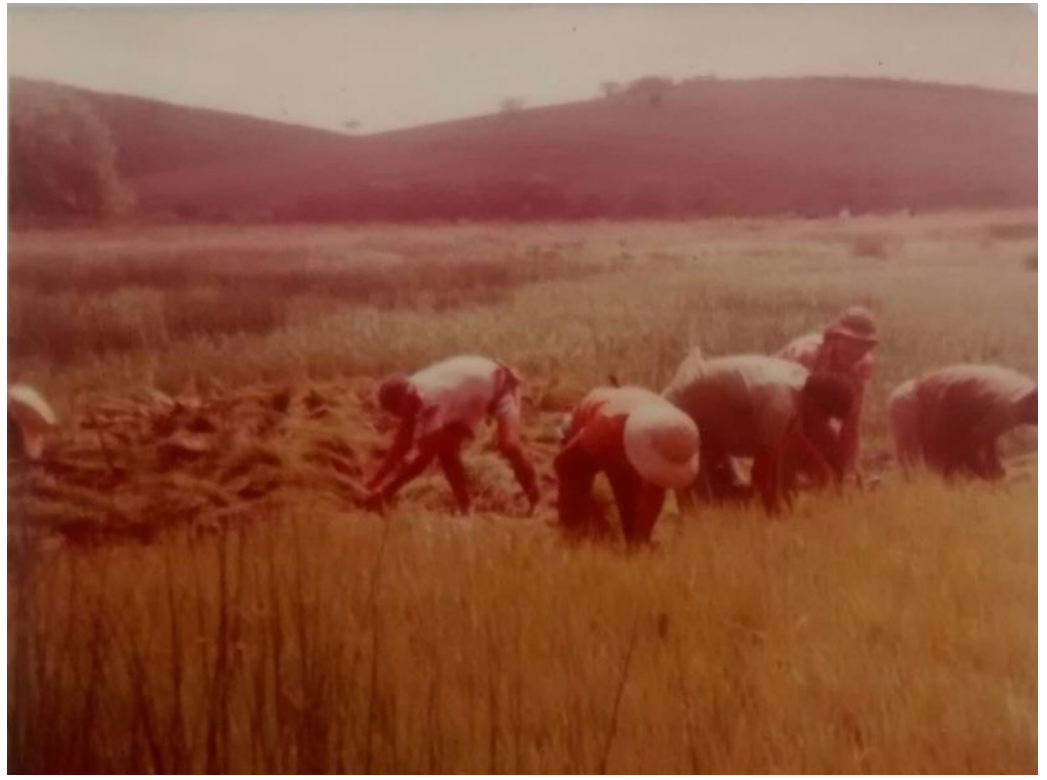

Fonte: Arquivo pessoal de Hélio da Silva Fialho,ex-supervisor de área do Mobral.

Essa fotografia demonstra o esforço de um grupo, que se agregava para fechar uma determinada parte do serviço proposto para aquele período do dia, mais conhecido como serviço de eito. A determinação dos trabalhadores em fechar o eito demonstra que o ritual do batalhão também era controlado pelo exercício de competição e, muitas vezes, de conflito entre os labutadores (BRANDÃO, 1995).

O plantio do arroz em terras do sertão alagoano exigia dos agricultores o manejo e o cuidado do cultivo tradicional da planta pois, sendo esse tipo de plantação extremamente dependente de muita água para a irrigação, tinha-se unicamente nos lagos deixados pelo rio, em épocas específicas do ano, a possibilidade de uma irrigação a partir da inundação das lagoas, favorecendo a plantação que, em princípio, se dava pela plantação de pequenas mudas nos ambientes alagados.

O período da colheita também era marcado pela observação e experiência dos sertanejos no cultivo do alimento, uma vez que a colheita deveria ser feita no tempo certo, 
assim como a secagem dos grãos, momento em que sua casca se solta e o grão está pronto para ser consumido.

A foto que se segue captura o Batalhão em uma das diversas lagoas formadas nas épocas da vazante do rio São Francisco. A imagem registra o encontro de homens e mulheres que achavam, nas lagoas deixadas pelas enchentes do rio, o sustento de suas famílias. Os ciclos de cheias do rio São Francisco ocasionavam o surgimento das referidas lagoas em determinadas épocas do ano. Esses territórios configuravam-se como uma fonte de produção e cultivo do arroz em terras do sertão.

A imagem captura, também, a chegada dos sertanejos ao local de trabalho, momento em que os homens observam o espaço de trabalho para a labuta daquele dia. Aguçando o olhar observamos a mulher que equilibra a quartinha d'água na cabeça, o que demonstra que, em uma jornada diária de trabalho, a água para consumo dos trabalhadores não poderia faltar, sob o risco de desidratação devido ao forte sol do sertão.

Assim como a quartinha d'água que aparece na imagem a seguir, observamos também nas Figuras 2 e 3 outros utensílios utilizados pelos sertanejos em suas jornadas de trabalho. A exemplo dos chapéus de palha e de couro; dos balaios e cestos de palha, as quartinhas e os potes feitos de argila. Esses objetos representam produções da cultura sertaneja, que têm ligação muito forte com o trabalho artesanal das mulheres e homens do campo. As quartinhas de barro, como conhecidas, ainda são muito utilizadas pelos agricultores em atividades no campo. Sua dimensão pequena facilita o manuseio, sem falar da sua principal função: conservar a água fria para o consumo durante todo o dia. A fotografia a seguir nos consente essas narrativas.

Figura 4 - O Batalhão na extinta Lagoa de Santiago

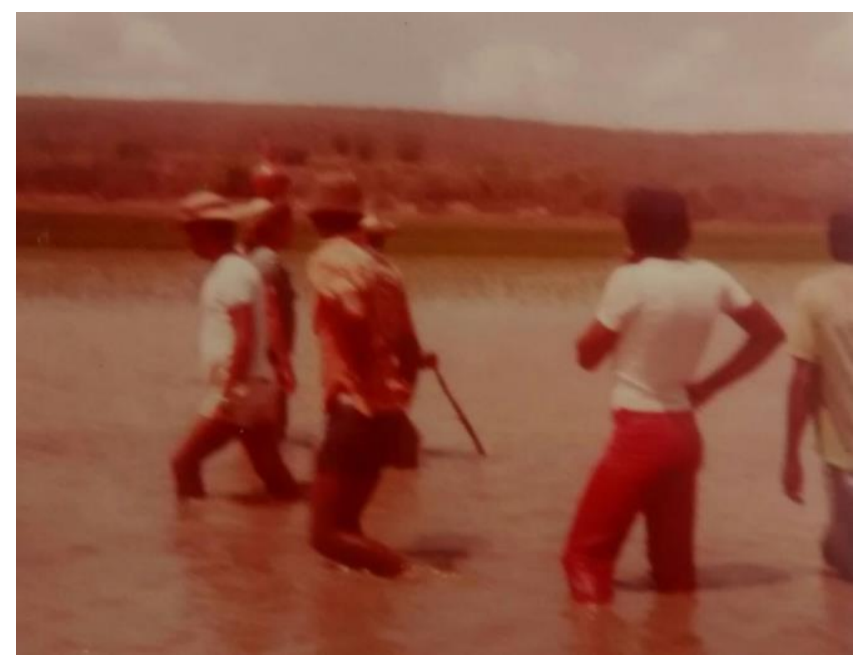


Fonte: Arquivo pessoal de Hélio da Silva Fialho, ex-supervisor de área do Mobral.

Devido aos longos períodos de estiagem que afetam as regiões margeadas pelo rio São Francisco, a formação das lagoas deixou de ser uma constante, o que pôs fim à cultura de produção do arroz em terras sertanejas. O desaparecimento das lagoas representou, para as comunidades ribeirinhas, o fim da produção de um cereal considerado integrante principal na alimentação dos sertanejos, e que adicionado ao feijão torna a alimentação equilibrada em proteínas, ao fornecer energia para o cumprimento das árduas tarefas diárias que envolvem, geralmente, o trabalho braçal.

Segundo Hélio Fialho, o Batalhão de Lagoa foi considerado uma das práticas culturais mais significativas registrada pela comissão do município de Pão de Açúcar à época. O narrador acrescentou que esta experiência foi selecionada inclusive para representar Alagoas em um evento realizado no Rio de Janeiro, em 1981. Naquele contexto, o Movimento, com suas intencionalidades, registrava os trabalhos que eram desenvolvidos nas comunidades, e passou a publicar essas iniciativas populares em uma coletânea de $28 \operatorname{livros}^{12}$, que recebeu o título de Projeto 28, e tinha por finalidade a socialização do modo de viver das pessoas em diferentes partes do país.

É importante salientar que o cultivo do arroz em mutirão, aproveitando a cheia das lagoas, certamente existia muito antes do Mobral Cultural. Essa prática cultural passou a ser apoiada pelo Mobral, numa ocasião propícia, e daí ter sido considerada pela Comissão do Município de Pão de Açúcar como uma das práticas culturais mais significativas. Entendemos que, neste caso, houve a apropriação pelo Mobral de uma forma de ação típica da cultura local.

\section{Considerações finais}

Compreendendo os sujeitos sertanejos como sujeitos ordinários e praticantes (DE CERTEAU, 2011), buscamos narrar no decorrer do texto a maneira como os sertanejos, praticantes culturais do Batalhão de Lagoa, interpretaram e lidaram com as informações doadas/impostas pelas ações do Mobral Cultural, naquele contexto de Ditadura, que, por sua vez, representava um poder ideológico do campo das estratégias (DE CERTEAU, 2011).

${ }^{12}$ Em suas narrativas, o ex-supervisor de área enfatizou que o registro das atividades do Batalhão de Lagoa foi destinado a uma publicação. Por não localizarmos registros da referida experiência nos documentos do Mobral encontrados na pesquisa, inferimos que a publicação dessa experiência pode não ter sido feita, ou permanece perdida, assim como muitos outros registros do Movimento. 
Seguindo o nosso objetivo, neste texto, de apresentar para os leitores as narrativas memorialísticas advindas de fontes orais e visuais de um interlocutor, que testemunhou as práticas culturais do Batalhão de Lagoa, dentro das ações do Programa Mobral Cultural, desenvolvidas no Município de Pão de Açúcar, mostramos aos leitores o sertão por outras lentes, rompendo com os estigmas criados e veiculados na história oficial.

As fontes orais e as imagens utilizadas como fontes constituíram narrativas que demonstram como os sertanejos recriaram e reconstruíram sentidos em suas culturas, segundo suas possibilidades de atuação no mundo, fazendo-se sujeitos a partir das experiências vividas. Permitiram, também, possíveis "respostas" às questões levantadas neste estudo, dando visibilidade, por meio da história oral, à memória dos sertanejos que participaram das ações culturais do Mobral através da prática genuína e tradicional do Batalhão de Lagoa.

O estudo demonstrou que os sujeitos sertanejos utilizaram as táticas de praticantes descritas por De Certeau (2011), ao se reapropriarem das ações do Mobral Cultural, recriando-as nos fios que tecem as tramas da cultura popular durante as interações proporcionadas pelo Programa, e considerando a visibilidade dada, conforme visualiza-se nas imagens e nos depoimentos no decorrer deste artigo.

No processo de investigação ficou explícito que os sertanejos deixaram-se ser invadidos pelo que não podiam controlar, mas resistiram com as múltiplas astúcias da sabedoria popular, ao mostrar o que sabiam fazer. Isso fez parte das "artimanhas" de resistência popular diante dos serviços e "novidades" oferecidos pelo Mobral; o que não significa dizer que o envolvimento da comunidade nas ações culturais representou a aceitação/passividade das ações apresentadas, pois quando essas ações foram implementadas, já existia uma estrutura social da cultura popular alicerçada nos costumes e tradições do povo do sertão.

Exemplos dessa realidade são praticantes que aparecem nas fotografias mostradas, acerca do Batalhão de Lagoa com seus ritos - que existiam muito antes do Mobral. Reconhecemos que, ao tempo em que o Movimento tentou apropriar-se das práticas culturais do povo sertanejo, acabou dando visibilidade ao Batalhão de Lagoa, uma das muitas manifestações grupais que apareceram no contexto das ações culturais, anteriormente dispersas no espaço nacional e guardando considerável distância da cultura oficial. 


\section{REFERÊNCIAS}

ALBERTI, Verena. Histórias dentro da história. In: PINSKY, Carla B. (Org.). Fontes históricas. São Paulo: Contexto, 2008. p. 155-202.

ALVES, Nilda; GARCIA, Regina Leite. Prefácio - Continuando a conversa. In: FERRAÇO, Carlos Eduardo; PEREZ, Carmem Lúcia Vidal; OLIVEIRA, Inês Barbosa de Oliveira (Orgs.). Aprendizagens cotidianas com pesquisa - novas reflexões em pesquisa nos/dos/com os cotidianos das escolas. Petrópolis: DP et Alii, 2008.

ANDRADE, Mário de. Dicionário Musical Brasileiro. Belo Horizonte: Editora Itatiaia, 1989.

ATLAS DO DESENVOLVIMENTO HUMANO NO BRASIL. Rio de Janeiro, PNUD, IPEA, Fundação João Pinheiro. Disponível em: http://www.atlasbrasil.org.br/2013/pt/. Acesso em: 04 mar. 2017.

BENJAMIN, Walter. Magia e Técnica, Arte e Política: ensaios sobre literatura e história da escrita. 8. ed. São Paulo: Brasiliense, 2012 (obras Escolhidas v.1).

BOSI, Ecléa. Memória e Sociedade: lembranças de velhos. 3. ed. São Paulo: Companhia das Letras, 1994.

BRANDÃO, Carlos Rodrigues. A partilha da vida. São Paulo: Geic/Cabral Editora, 1995.

BRANDÃO, Carlos Rodrigues. A educação como cultura. Campinas: Mercado das letras, 2002.

FUNDAÇÃO MOVIMENTO BRASILEIRO DE ALFABETIZAÇÃO. Documento Básico Mobral. Rio de Janeiro, 1975.

CARTIER-BRESSON, Henri. O momento decisivo. In: Fotografia e Jornalismo. Bacellar, Mário Clark (Org.). São Paulo, Escola de Comunicações e Artes (USP), 1971, p. 19-26.

CASTRO, Josué de. Geografia da fome: o dilema brasileiro: pão e aço. 10 ed. Rio de Janeiro: Antares, 1984.

DE CERTEAU, Michel. A invenção do cotidiano: 1 Artes de fazer. 17. ed. Petrópolis: Vozes, 2011.

DE CERTEAU, Michel. A cultura no plural. 7. ed. Campinas: Papirus, 2012.

PÉREZ, Carmen Lúcia V.; AZEVEDO, Joanir G.de. Apontamentos de aulas: questões teórico-metodológicas a respeito dos estudos com o cotidiano. In: FERRAÇO, Carlos Eduardo; PÉREZ, Carmen Lúcia V.; OLIVEIRA, Inês B. (Org.). Aprendizagens cotidianas com a pesquisa: novas reflexões em pesquisa nos/dos/com os cotidianos das escolas. Rio de Janeiro: Ed. Dp et Alii, 2008.

FREIRE, Paulo. Extensão ou comunicação. 15. ed. São Paulo: Paz e Terra, 2011. 
GERMANO. José Willington. Estado militar e educação no Brasil (1964-1985). 5. ed. São Paulo: Cortez, 2011.

LEITE, Miriam Moreira. Retratos de família. São Paulo: Edusp, 1993.

MELO, Adriana Ferreira: O lugar-sertão: grafias e rasuras. Orientador: Cássio Eduardo Viana Hissa. 2006. 131f. Dissertação. (Mestrado em Geografia) - Instituto de Geociências, Universidade Federal de Minas Gerais, Belo Horizonte, 2006. Disponível em:

http://hdl.handle.net/1843/MPBB-6VRHHG. Acesso em: jan 2020.

OLIVEIRA, Inês Barbosa de. O currículo como criação cotidiana. Petrópolis: DP et Alii; Rio de Janeiro: FAPERJ, 2012.

THOMPSON, Edward Palmer. Costumes em comum: estudos sobre a cultura popular tradicional. São Paulo: Companhia das Letras, 1998.

\section{Como referenciar este artigo}

SILVA, Jailson Costa da; FREITAS, Marinaide Lima de Queiroz. Memórias do batalhão de lagoa: prática cultural das comunidades rurais do sertão de Alagoas. Revista IberoAmericana de Estudos em Educação, Araraquara, v. 15, n. 2, p. 451-468, abr./jun. 2020. eISSN: 1982-5587. DOI: https://doi.org/10.21723/riaee.v15i2.12775

Submetido em: 22/04/2019

Revisões requeridas: 30/06/2019

Aprovado em: 27/09/2019

Publicado em: 20/02/2020 